\title{
Semi-Rigid Pneumatic Ureteroscopicremoval of Ureteric Stone; Seven Years Experience At Nepalgunj Medical College
}

\author{
Shrestha NM
}

\begin{abstract}
Background: The present study aimed to report the outcomes of ureteroscopy (URS) treatment of ureteric stone with semi-rigid pneumatic ureteroscopic lithotripsy. Method: This was a prospective observational study of the patients who underwent ureteroscopic removal of ureteric stone in the department of surgery, urology unit, Nepalgunj Medical college from January 2009 to July 2015. All patients underwent urereroscopic removal of stones located at different levels of the ureter using semi-rigid $8 / 9.8 \mathrm{Fr}$ ureteroscope. Result: 1251 patients with ureteric stones who underwent URS during the study period. Out of 1251 patients, in 1211 (96.80\%) stone was removed in first setting, $10(0.79 \%)$ patients needed second setting of URS to remove stones. The overall failure rate was $1.59 \%$. The common complications of URS observed were perforations of the ureteric wall (20\%), retropulsion of ureteric stone into kidney (35\%) and urosepsis(45\%) which necessitated ureterolithotomy, Extra Corporeal Shock Wave Lithotripsy (ESWL) and antibiotic therapy, respectively. Two (0.15\%) patients died and the cause was urosepsis with multiorgan failure in both. Conclusion: Most of the ureteric stone can be removed in a single setting of URS. However, some complications such as, ureteral trauma, difficulty in fragmentation of a stone, retropulsion of stone into the kidney and a fatal urosepsismay occur in few cases. Therefore, URS is a useful modality to remove the ureteric stones despite its few complications.
\end{abstract}

Key words: ESWL, lithotripsy, ureteroscopy, ureteric Stone, urosepsis, ureterolithotomy

\section{INTRODUCTION}

Ureteroscopy has become routine urological operation to diagnose and treat ureteral disorder like stone formation, stricture, malignancy and bleeding lesion atureter ${ }^{1,2}$. In most cases semi-rigid uretoroscopy are safe and effective, however, in certain situations this procedure cannot be easily performed and also failed the procedure. The cause of failure may be due to some pathological ureter like stricture ureter (calculus/neoplastic/congenital/non congenital), tiny ureter, tortuous ureter, a surgeon's experience, type and caliber of ureteroscopic, location of stone as well as previous history of $\mathrm{ESWL}^{3-5}$.

There are different modalities of treatment for ureteric stone; surgical (Ureterolithotomy, ESWL, Ureteroscopic) and conservative. Ureterolithotomy can be done for the stone located at any part of ureter but it has some drawback of difficultly in removing stones at mid and lower part of ureter, attempting second surgery from the same site, long hospital stay and scar formation ${ }^{6}$. ESWL can be other modality of treatment for upper ureteric stone because of its simplicity, non invasiveness and minimum morbidity. However, some stones are difficult to break due to its hardness and the fragments may remain in the ureter even after successful

Dr. Naresh Man Shrestha

Address for correspondence:

Dr. Naresh Man Shrestha

Department of Urology

Nepalgunj Medical College Teaching Hospital,

Kohalpur, Banke, Nepal

Email: drnms1973@gmail.com fragmentation. Impacted stone (when stone remains at the same site for more than 2 months) ${ }^{7}$ are also more difficult to fragment with ESWL because of lack of natural expansion space for stone in ureter ${ }^{8,9}$.

Ureteroscopic lithotripsy can be considered as a safe and useful treatment modality ${ }^{10}$. There are semi rigid and flexible uretreroscopy. The semi-rigid URS has different types of source of energy to break stone such as, electrohydraulic, ultrasonic and pneumatic where as, the flexible URS has holmium laser with electrohydraulic and ultrasonic, which has more risk ofcomplications like ureteral perforation. The URS with Pneumatic energy is strong enough to fragment all types of stone and is cheaper than laser URS. However semi-rigid URS has also high chance of retropusion of stone ${ }^{11}$.

This study presents my seven years experience in treating ureteric stones with semi-rigid pneumatic ureteroscopeat Nepalgunj Medical College.

\section{MATERIAL AND METHOD}

It is a prospective observational study including all patients above 12 years who underwent Ureteroscopic removal of ureteric stone in the Surgery department, Urology unit, in Nepalgunj Medical College Teaching Hospital during the period from January 2009 to July 2015. All patients who fulfilled the inclusion criteria underwent URS after taking the informed consent. Patient with uncorrected coagulopathy, active untreated urinary tract infection (UTI), pregnancy and age under 12 years were excluded in the study.

Patients were treated with antibiotic prior to operation. Ultrasonography of abdomen and pelvis, kidney-ureter- 
bladder (KUB) X-ray and intravenous urogram (IVU) were performed. Furthermore, the patients were studied for clinical history, clinical examination and routine laboratory investigation. Operative technique: For removal of stone, 8/9.8 $\mathrm{Fr}$ wolf semi-rigid pneumatic ureteroscope, flourscope (C-arm), video monitor, stone grasper, lithoclast and irrigating device were used. After inserting a safety guide wire, ureteroscopewas introduced inside the ureter, the visualized stone was fragmentedunderdirect vision by maintaining low pressure normal salineirrigation system.

In very tortuous ureter, Jeromin maneuver and double guide wire technique were used to reach up to stone. Stone fragments were taken outby grasper. In some cases, stone fragment could not be taken out due to its softness and tiny size. At the end of procedure, a double $\mathrm{j}$ (DJ) stent was placed for 3 weeks. Before removal of DJ stent, X-ray KUB was done to conform for any residual stone ${ }^{12}$.

Data analysis: All the generated data were of qualitative variable, which were presented as frequency and percentage.

\section{RESULTS}

1251 patients were eligible for the study and all of them underwent URS. Among them 826(66.02\%) were male and $425(33.97 \%)$ were female. The male to female ratio was 1:1.94. The age ranged from 12 to 65 years.

There were 325(25.97\%) patients with upper ureteric stones, $775(61.95 \%)$ with mid ureteric and $151(12.07 \%)$ with lower ureteic stones Table I. In 1211(96.80\%) patients stone was removed in single setting and in $10(0.79 \%)$ stone was removed in double settings.

\begin{tabular}{|l|c|c|}
\hline & No. of Pts. & \% \\
\hline Male & 826 & $66.02 \%$ \\
\hline Female & 425 & $33.97 \%$ \\
\hline Upper ureteric & 325 & $25.97 \%$ \\
\hline Mid ureteric & 775 & $61.95 \%$ \\
\hline Lower ureteric & 151 & $12.07 \%$ \\
\hline
\end{tabular}

Table I: Demography and level of ureteric stones. $(n=1251)$

\begin{tabular}{|l|c|c|}
\hline Settings & No. of Pts. & \% \\
\hline Single setting & 1211 & $96.80 \%$ \\
\hline Double settings & 10 & $0.79 \%$ \\
\hline
\end{tabular}

Table II: Stone clearance $(n=1221)$

\begin{tabular}{|l|c|c|}
\hline Complications & No. of Pts. & \% \\
\hline Perforation of ureteric wall & 4 & $20 \%$ \\
\hline Retropulsion into stone & 7 & $35 \%$ \\
\hline Uro sepsis & 9 & $45 \%$ \\
\hline
\end{tabular}

Table III: Complications $(n=20)$

\begin{tabular}{|l|c|c|c|}
\hline Complications & Management & No. of Pts. & $\%$ \\
\hline $\begin{array}{l}\text { Perforation of } \\
\text { ureteric wall }\end{array}$ & Ureterolithotomy & 4 & $20 \%$ \\
\hline $\begin{array}{l}\text { Retropulsion } \\
\text { of stone }\end{array}$ & ESWL & 7 & $35 \%$ \\
\hline Urosepsis & Conservative & 7 & $35 \%$ \\
\hline Mortality & & 2 & $0.15 \%$ \\
\hline
\end{tabular}

Table IV: Management where URS was failed $(n=20)$

\section{DISCUSSION}

The present study revealed that out of 1251 patients with ureteric stones, stones of $1211(96.80 \%)$ patient were being removed successfully in a single setting URS. This finding has been supported by guidelines on urolithiasis ${ }^{13}$ and study of M.El-Qadhi ${ }^{14}$. Furthermore, out of 1251 patients, 10(0.79\%) patients needed double setting URS due to presence of hard stones and pus efflux after dislodging stone.

Among 10 patients, 6 patients had hard stone and 4 patients had pyonephrosis. To the patients with pyonephrosis, DJ stent was kept in situ till the urine culture report showed negative result for pus but kept not more than three months. To the patient with hard stone, the stones were removed in the next setting. This study showed comparatively higher success rate in first setting of URS (96.80\%) than the study of Jermomin Let al. (86.6\%). Furthermore, this study showed the lower rate to conduct the second setting of URS $(0.79 \%)$ than the study of Jermomin Let al. $(13.40 \%)^{15}$.

In the present study five patients $(0.39 \%)$ with gross ureteral trauma and ureteral stricture were observed in URS and had to be coverted to ureterolithotomy. This finding was supported by the study of Jeromin L et al., which mentioned the perforation of the ureteral from URS, which necessitated surgery in $0.29 \%$ of patients.

The sixteen patients $(1.27 \%)$ whose stones were migrated to kidney during fragmentation in URS andneeded further treatment with ESWL. This type of complication was observed in the patients with the stone located mainly at the upper ureter. The same complication was also mentioned in the study of Mitre Al et al. ${ }^{11}$, and the method used for management of this complication was mentioned in Lingeman JE et al. study ${ }^{12}$.

Nine patients (45\%) suffered from urosepsis and treated with broad spectrum antibiotics which was been also reported in the study of Hossain GM Z et al. ${ }^{16}$. 


\section{CONCLUSION}

The present study showed the high rate ofstone clearance in single setting URS, however, there are some complications associated with the method, such as, gross ureteral trauma, retropulsion of the ureteric stone to the kidney, urosepsis and death due to septic shock which should be well managed for successful operative outcome.

\section{REFERENCES}

1. Preminger GM, Tiselius HG, Assimos DG, Alken P, Buck AC, Gallucci M, Knoll T, Lingeman JE, Nakada SY, Pearle MS, Sarica K, Türk C, Wolf JS Jr. 2007 Guideline for the management of ureteral calculi. Eur Urol.2007;52:1610-1631.

2. Phillips $C K$, Landman J. Lasers in the upper urinary tract for nonstone disease. World J Urol. 2007;25:249-256.

3. Abdelrahim AF, Abdelmaguid A, Abuzeid H, Amin M, Mousa el-S, Abdelrahim F. Rigid ureteroscopyfor ureteral stones: factors associated with intraoperative adverse events. J Endo Urol. 2008;22:277-280.

4. Schuster TG, Hollenbeck BK, Faerber GJ, Wolf JS Jr. Complications of ureteroscopy: analysis of predictive factors. J Urol. 2001;166:538-540.

5. Leijte JA, Oddens JR, Lock TM. Holmium laser lithotripsy for ureteral calculi: predic- tive factors for complications and success. J Endourol. 2008;22:257-260.

6. Anderson EE.Ureterolithotomy.In: Glenn JF, ed. Urologic surgery, $4^{\text {th }}$ ed.philaldelphia: JB Lippincott,1993:276-286. 7.Roberts WW, Cadeddu JA, Micali S, Kavoussi LR, Moore RG.Ureteral stricture formation after removal of impacted calculi. J Urol. 1998;159:723-726.

8. Mueller SC, Wilbert D, Thueroff JW, Alken P. Extracorporeal shock wave lithotripsy of ureteral stones: clinical experience and experimental findings. J Urol. 1986;135:831-834.

9. Chaussy CG, Fuchs GJ: Current state and future developments of noninvasive treatment of human urinary stones with extracorporeal shock wave lithotripsy. J Urol. 1989;141:782-789.

10. Biri H, Kupeli B, Isen K, Sinik Z, Karaoglan U, Bozkirli I. Treatment of lower ureteral stones: extracorporeal shockwave lithotripsy or intracorporeal lithotripsy? J Endourol. 1999;13:77-81

11. Mitre Al, Chambo JL, Arap S.Ureteroscopy. In: Glenn's Urologic Surgery. Philadelphia, Lippincott-Raven Publishers.1998; p942945.

12. Lingeman JE Matlaga BR, Evan AP. Campbell-Walsh urology, $9^{\text {th }}$ ed. Philadelphia:Elsevier. 2007.p1508-1525.

13. Tiselius HG, Ackermann D, Alken P. Working party on lithiasis. European Association of Urology.Guidelines on Urolithiasis.Eur Urol. 2001;40(4):362-371.

14. M. El-Qadhi. Outcome of ureteroscopy for the management of distal ureteric calculi: 5-years' experience. AFJU. 2015;21:67-71.

15. Jeromin L, Sosnowski M. Ureteroscopy in the Treatment of Ureteral Stones: Over 10 Years' Experience. Eur Urol. 1998;34:344-349.

16. Hossain GM, Hasan MR, Rahman M, Ahmed $M$. Ureterorenoscopy and pneumatic Lithotripsy in the management of ureteral calculus. JCMCTA. 2008;19(1):11-14. 